\title{
The Relationship between the Age of Menarche and Premarital Sexual Behaviors of Adolescence and Young Adults in Indonesia: Analysis on Survey Data of Indonesian Adolescencets' Reproductive Health in 2012
}

\author{
Nuraliah \\ Master of Public Health Program, Faculty of Medicine, Universitas Gadjah Mada \\ Indonesia
}

\section{Abstract}

One crucial period of woman's development period is when the age of puberty is begun, indicated by menarche. The age of menarche might be related to a certain sexual that one having earlier menarche is potential to do premarital sexual behaviors. The aim of this research is to analyze the relationship between the age of menarche and premarital sexual behaviors. This research is quantitative research employing secondary data: The Survey of Indonesian Adolescents' Reproductive Health (SKRRI, Survey Kesehatan Reproduksi Remaja Indonesia) in 2012. The data design hired was the cross sectional survey. Women at the age of 15-24 years-old were chosen as the research population. There were 7,367 samples involved, taken from both urban and rural areas. The dependent variable of this research was the premarital sexual behaviors categorized into non risky behaviors (holding hands) and risky behaviors (kissing, petting, and having sexual intercourse); while the independent variable was the age of menarche. The external variables of this research consisted of age, education, and domicile. This researcher used the univariable analysis, bivariable analysis utilizing the chi-square, and multivariable analysis applying the logistic regression with the confidence level of $95 \%$ and value of $p=0.005$. The results show that the average age of menarche is thirteen years-old and premarital sexual behaviors are mostly performed by urban women. Based on the results of relationship test, the age of menarche does not have any significant relationship with premarital sexual behaviors. However, there is a significant relationship between premarital sexual behavior with the age and domicile.

Keywords: reproductive health, the age of menarche, sexual behavior

\section{Introduction}

\section{Research Background}

Puberty is a transition period between childhood and adulthood. The peak of puberty is indicated by menarche or the first menstruation undergone by an adolescent girl 
(Mary \& Carol, 2003). Earlier menarche that occurs when a child has not reached maturity of mind and still lacks of relevant knowledge causes various psychological responses to her.

The age of menarche is perceived as a crucial period since it is one indicator of reproductive health, population health, and future chronic disease (Islam et al., 2017). The shift of age of menarche indicating earlier menarche becomes a wide concern since it happens in almost all of countries, including low and middle income countries (Blum et al., 2014). This trends also sweeps Indonesia. The data of Riskesdas 2010 (Riset Kesehatan Dasar, Research of Fundamental Health) point out that as much as $40.7 \%$ and $32 \%$ adolescents had their menarche at the age of thirteen years-old and twelve years-old, respectively. Another research conducted by Suryansyah (2013) shows that adolescent begins their puberty at the age of nine to ten years-old (48.2\%) and at the age of twelve to thirteen years-old, they all have had their puberty.

Research conducted by Yermachenko \& Dvornyk (2014) indicates that early menarche triggers sexual behaviors and pregnancy in adolescent leading to early marriage. An adolescent with earlier menarche is potential for performing premarital sexual behaviors due to her emotional immaturity to control herself. Several studies figure out that those sexual behaviors are begun at the age of thirteen years-old. They include hugging, kissing, groping sensitive areas, and having sexual intercourse (Schwartz, 2010; Smith et al., 2003).

In developed countries, the increase of prevalence of sexual activities among adolescents is shown by the number of girls in America having intercourses that increased from 7\% in 1950 to 40\% in 1982 (Brooks-Gunn \& Furtstenberg Adolescent, 1989). A certain study in UK conducted in 1960 s figures out that $12 \%$ of girls had had sexual intercourse. However, the study also reveals that ten years later, $50 \%$ of girls at the age of sixteen to nineteen years-old were reported for having lost their virginity (Farrel, 1978). Observed from the demography of adolescents, more than a half of sexually active adolescents (53.5\%) live in rural areas and it is reported that they have more than one sexual partners (29.5\%). In Indonesia, the data of Survey of Indonesian Adolescents' Reproductive Health in 2007 indicate that adolescents having premarital sexual intercourse were as much as 801 out of 18,510 .

There are still limited literatures discussing the relationship between the age of menarche and sexual experiences in Indonesia. Research conducted by Deardoff et al., (2005) reveals that there is indeed a relationship between sexual behaviors and the age of menarche. However, that research uses relatively small sample and is European-countries based. Hence, this research was purposively designed to observe the relationship between the age of menarche and specific sexual experiences; such as holding hands, kissing, petting, and having sexual intercourse on adolescents and young adults in Indonesia by employing the data of Survey of Indonesian Adolescents' Reproductive Health. 


\section{Research Objectives}

To observe and analyze the relationship between the age of menarche and sexual behaviors on adolescents and young adults.

\section{Methodology}

This research is cross sectional study research hiring the data of Indonesian Demographic Health Survey (SDKI, Survey Demografis Kesehatan Indonesia) in 2012 containing the data of sub-survey of Reproductive Health of Adolescents with the population of all adolescents and young adults at the age of 15-24 years-old in Indonesia. The researcher applied the cross sectional study design to analyze the relationship between determining factors and their effects by using the observational approach or gathering data in a certain place (Rosner, 2010). This research involved respondents of Indonesian Demographic Health Survey in 2012 that were 8,902 girls. Those girls were selected based on inclusion criteria: female and having had menarche. Exclusion criteria of this research were respondents with 'not knowing' answers on questions related to the research variables. Those both criteria minimized the sample to be 7,367 .

The dependent variable in this research was the premarital sexual behaviors categorized into non risky behaviors (holding hands) and risky behaviors (kissing, petting, and having sexual intercourse); while the independent variable was the age of menarche. The external variables of this research were age, education, and domicile. The univariable analysis was conducted by finding the distribution of respondents' characteristics, performed by observing the distribution of frequency and the proportion of each group. The bivariable analysis was conducted by utilizing the chi square to figure out the relationship between the dependent and the independent variables as well as between the external and the dependent variables. The influence of independent variables towards the dependent variables involving external variable was found out by performing the multivariable analysis by hiring the logistic regression with the confidence level of $95 \%$ and the value of $p=0.0005$.

\section{Findings}

Table 1 displays the chosen sample has a double proportion for the adolescent age (66.96\%), larger than the proportion for the young adult age that is $33.04 \%$. The biggest proportion of education level is reached by the respondents graduating from senior high school (51.57\%); while the respondents graduating from tertiary schools (university/academy) have a proportion as much as $26.17 \%$. The selected respondents mostly come from urban areas. 


\section{Table 1 The Distribution of Respondents' Characteristics}

\begin{tabular}{lll}
\hline Variable & $\mathrm{n}$ & $\%$ \\
\hline Age & & \\
Adolescent (15-19 years-old) & 4,933 & 66.96 \\
Young adult (20-24 years-old) & 2,434 & 33.04 \\
Education & 492 & 6.68 \\
Primary school & 1,369 & 18.58 \\
Junior high school & 3,799 & 51.57 \\
Senior high school & 1,707 & 26.17 \\
Tertiary education & & \\
Domicile & 4,523 & 61.40 \\
Urban & 2,844 & 38.60 \\
Rural & & \\
The age of menarche & 479 & 6.50 \\
<12 years-old & 5,460 & 74.11 \\
12-14 years-old & 1,428 & 19.38 \\
$>14$ years-old & & \\
Sexual behaviors & 4,836 & 34.36 \\
Risk & 2,531 & 65.64 \\
Non risk & & \\
\hline
\end{tabular}

The age of menarche is when a woman has her first menstruation. The respondents' age of menarche involved in the research ranges from nine to twenty years-old. They had their menarche at the age of thirteen years-old on average. The largest proportion of age of women having their menarche is at the age of twelve to fourteen years-old $(74.11 \%)$. There are only $6.50 \%$ women having their menarche at the age of less than twelve years-old.

Based on the Central Agency of Statistics (BPS, Badan Pusat Statistik) in 2012, sexual behaviors consist of dating behavior including holding hands, kissing, petting, and having coitus. In this research, sexual behaviors are divided into the risky and non risky sexual behaviors. A sexual behavior is categorized as risky if in the forms of kissing, petting, and/or having coitus and non risky if there are no kissing, petting, and having coitus. Table 2 indicates that one third of respondents have conducted risky and non risky premarital sexual behaviors.

Table 2 The Distribution of Risky and Non-Risky Premarital Sexual Behaviors

\begin{tabular}{llllll}
\hline \multirow{2}{*}{ Variable } & \multicolumn{3}{c}{ Safe } & \multicolumn{3}{c}{ Unsafe/Risky } & P-value \\
\cline { 3 - 5 } & $\mathrm{n}$ & $\%$ & $\mathrm{n}$ & $\%$ & \\
\hline Age & & & & & \\
Teenage (15-19 years-old) & 3,554 & 73.49 & 1,379 & 54.48 & 0.000 \\
Young adult (20-24 years-old) & 1,282 & 26.51 & 1,152 & 45.52 & \\
Education & & & & & \\
Primary school & 326 & 6.74 & 166 & 6.56 & 0.000 \\
Junior high school & 994 & 20.55 & 375 & 14.82 &
\end{tabular}




\begin{tabular}{llllll}
\hline \multirow{2}{*}{ Variable } & Safe & \multicolumn{3}{l}{ Unsafe/Risky } & P-value \\
\cline { 2 - 5 } & $\mathrm{n}$ & $\%$ & $\mathrm{n}$ & $\%$ \\
\hline Senior high school & 2,567 & 53.08 & 1,232 & 48.68 & \\
$\begin{array}{l}\text { Tertiary education } \\
\text { Domicile }\end{array}$ & 949 & 19.62 & 758 & 29.95 & \\
$\begin{array}{l}\text { Urban } \\
\text { Rural }\end{array}$ & 2,004 & 41.44 & 840 & 33.19 & 0.000 \\
The age of menarche & 2,832 & 58.56 & 1,691 & 66.81 & \\
<12 years-old & & & & & \\
$12-14$ years-old & 314 & 65.55 & 165 & 34.45 & 0.227 \\
$>14$ years-old & 3,612 & 66.15 & 1,848 & 33.85 & \\
\hline
\end{tabular}

A double distribution of experiences in performing risky premarital sexual behaviors is found on adult women (32.67\%) if compared to distribution found on adolescent girls (15.29\%). A high distribution of experiences in performing risky premarital sexual behaviors is also discovered on the respondents whose education level is senior high school (48.68\%). The percentage of risky sexual behavior increases along with the higher level of education yet it decreases when the respondents have a high education. Furthermore, the high percentage is also found on adolescents and young adult women living in urban areas (66.81\%). During the age of menarche, women with earlier menarche (less than twelve years-old) and late menarche (more than fourteen years-old) possess a bigger proportion of conducting risky sexual behaviors.

To figure out factors triggering adolescents to perform risky and non risky sexual behaviors, the researcher conducted a further test that was the logistic regression by involving all variables, either independent or external variables. The test resulted pvalue (Prob $>\mathrm{chi}^{2}$ ) as much as 0.03 that meant there were significant influences of independent variables towards the dependent variables.

\section{Table 3 Odd Ratio, Confident Interval, and P-value of Sexual Behaviors}

\begin{tabular}{|c|c|c|c|c|}
\hline \multirow{2}{*}{$\begin{array}{l}\text { Variables } \\
\text { Age }\end{array}$} & \multicolumn{4}{|c|}{ Risky Sexual Behaviours } \\
\hline & $O R$ & $95 \% \mathrm{CI}$ & & $P$-value \\
\hline \multicolumn{5}{|l|}{ Age } \\
\hline Adolescent (15-19 years-old) & Ref & & & \\
\hline Young adult (20-24 years-old) & 2.130674 & 1.894858 & 2.395838 & 0.000 \\
\hline \multicolumn{5}{|l|}{ Education } \\
\hline Primary school & Ref & & & \\
\hline Junior high school & .8578326 & 0.6835969 & 1.076478 & 0.186 \\
\hline Senior high school & 1.021387 & 0.8322406 & 1.253521 & 0.840 \\
\hline Tertiary education & 1.09334 & 0.8769863 & 1.363068 & 0.428 \\
\hline \multicolumn{5}{|l|}{ Domicile } \\
\hline Urban & Ref & & & \\
\hline Rural & 1.250736 & 1.125762 & 1.389584 & 0.000 \\
\hline \multicolumn{5}{|l|}{ The age of menarche } \\
\hline$<12$ years-old & Ref & & & \\
\hline
\end{tabular}


After involving all variables, the result of logistic regression indicates that only the variables of age and domicile that significantly influence risky sexual behaviors. The values of Odds Ratio as much as 2.51 and CI (1.894858-2.395838) point out that adult women are more prone to conduct risky sexual behaviors 2.1 times if compared to teenage girls. In the variable of domicile, the value of Odds Ratio is 1.2, showing that adolescents and young adults living in urban areas possess 1.2-times potentiality to do riskpremarital sexual behaviors. Moreover, the variables of education, domicile, and age of menarche indicate no significant relationship. This test publishes similar results to results of bivariate test where only the variables of age and domicile that show a significant relationship.

\section{Discussion}

Entering the age of puberty indicated by the age of menarche is a woman's critical period. The age of menarche has been widely perceived as one of indicators determining the reproductive health of all ages. The results of research suggest that the average age of menarche is thirteen years-old, either in urban or rural areas. Those results are similar to results of research conducted by Suryansyah (2013) concluding that all teenage girls in urban areas have had their puberty indicated by having menarche at the age of twelve to thirteen years old. Affandi, B. (1991), quoted by Soejoeti (2001) conveys that one hundred years ago, there was a woman having her first period at the age of seventeen years-old. Nowadays, a teenage girl has her first period at the age of twelve years-old or maybe less due to relatively improved nutrition and stimulations of visual and audio media (radio, TV, movies, and magazines) that accelerate biological maturity.

This research figures out that the number of adolescents and young adults conducting risksexual behaviors is less than the number of adolescents and young adults that do not conduct sexual behaviors. One out of three women of this research has performed risky sexual behaviors. This is due to the fact that premarital sexual intercourses are not supported by Indonesian cultures.

In line with the research conducted by Pinandari (2015) stating that premarital sexual behaviors are more frequently found in urban than rural areas, this research indicates that women whose domicile is in urban areas perform more sexual behaviors than women in rural areas. Age possesses a significant influence towards sexual behaviors. Adults conduct more sexual behaviors than adolescents since they have more experiences.

The researcher did not find any significant relationship between education and risky sexual behaviors. Pinandari (2015) finds out that in Indonesia, either adolescents or young adults do not accept any formal education related to reproductive health; they 
only have information of contraception methods. Hence, either women with low or high education have the same possibility in performing risky sexual behaviors.

This research also shows that the age of menarche does not significantly influence sexual behaviors. Nevertheless, women with early menarche and women with late menarche are more potential to conduct risky sexual behaviors if compared to women with average or normal menarche. Irwin and Millstein (1998) believe that adolescents' risky behaviors are the manifestation of asynchronous pubertal maturation or too early/late maturity. This triggers them to perform risky behaviors; such as consuming alcohols and drugs as well as having premarital sexual intercourses.

\section{Conclusion}

This research concludes that the average age of menarche is thirteen years-old and that risky behaviors have less proportion when compared to risky sexual behaviors. Women living in urban areas are more potential in having risky behaviors. There is no significant relationship between the age of menarche and risky sexual behaviors, respectively. Young adult women living in urban areas tend to do more risky premarital sexual behaviors than adolescent girls living in rural areas.

\section{Acknowledgments}

I would like to thank to Indonesia Endowment Fund for Education (LPDP) Ministry of Finance Republic Indonesia for gorgeously supporting author by scholarship. My parents, brothers and sister thanks for your pray. The last all my friends in Yogyakarta and Sulawesi for being together, your support and encouragement was worth more than I can express on paper.

\section{References}

[1] Blum, R. W., Astone, N. M., Decker, M. R., \& Mouli, V. C. (2014). A Conceptual Framework for Early Adolescence : A Platform for Research. International Journal Adolescence Medical Health, 26(3), 321-331. doi:10.1515/ijamh2013-0327

[2] Brooks-Gunn J, F. F. J. (1989). Adolescent Sexual Behavior. The American Psychology, 44(2), 249-257.

[3] Deardorff, J., Gonzales, N. A., Christopher, F. S., Roosa, M. W., Millsap, R. E., \& Objective, A. (2005). Early Puberty and Adolescent Pregnancy : The Influence of Alcohol Use. Pediatrics, 116(6). doi:10.1542/peds.2005-0542

[4] Islam, S., Hussain, A., Islam, S., Mahumud, R. A., Biswas, T., Mohammed, S., \& Islam, S. (2017). Age at Menarche and Its Socioeconomic Determinants among Female Students in an Urban Area in Bangladesh. Sexual \& Reproductive Healthcare. doi:10.1016/j.srhc.2017.03.008 
[5] Mary, J., \& Carol, V. (2003). Women's Reproductive Health, from Menarche to Menopause. United Stated of America: Michigan, Inc Printed.

[6] Pinandari, A. (2015). Pendidikan Kesehatan Reproduksi sebagai Pencegah Perilaku Hubungan Seksual Pranikah Remaja dan Dewasa Muda di Indonesia (Analisis Data SDKI 2012).

[7] Schwartz, I. M., \& Schwartz, I. M. (2010). Comparison Affective Reactions of American and Swedish Women to Their First Premarital Coitus: a Crosscultural Comparison, (February 2015), 37-41. doi:10.1080/00224499309551674

[8] Smith, A., Agius, P., Dyson, S., \& Mitchell, A. (n.d.). Health 2002.

[9] Soejoeti, S. Z. (2001). Perilaku Seks di Kalangan Remaja dan Permasalahannya. Media Litbang Kesehatan, 11, 30-35.

[10] Suryansyah, A. (2013). Puberty Stages of Primary School Students. In International Journal of Pediatric Endocrinology (Vol. 2013, p. P82). BioMed Central Ltd. doi:10.1186/1687-9856-2013-S1-P82

[11] Yermachenko, A., \& Dvornyk, V. (2014). Nongenetic Determinants of Age at Menarche: a Systematic Review. Biomed Research International, 2014, 1-15. 